BMJ Open

Diabetes

Research

\& Care

\section{Impact of type 2 diabetes and microvascular complications on mortality and cardiovascular outcomes in a multiethnic Asian population}

To cite: Yap J, Anbalakan K Tay WT, et al. Impact of type 2 diabetes and microvascular complications on mortality and cardiovascular outcomes in a multiethnic Asian population. BMJ Open Diab Res Care 2021;9:e001413. doi:10.1136/ bmjdrc-2020-001413

- Additional supplemental material is published online only. To view, please visit the journal online (http://dx.doi. org/10.1136/bmjdrc-2020001413)

JY and KA contributed equally.

Received 27 March 2020 Accepted 17 June 202

\section{Check for updates}

(c) Author(s) (or their employer(s)) 2021. Re-use permitted under CC BY-NC. No commercial re-use. See rights and permissions. Published by BMJ.

For numbered affiliations see end of article.

Correspondence to Dr Khung Keong Yeo; yeo.khung.keong@singhealth. com.sg

\section{ABSTRACT}

Introduction Diabetes mellitus is a growing public health epidemic in Asia. We examined the impact of type 2 diabetes, glycemic control and microvascular complications on mortality and cardiovascular outcomes in a multiethnic population-based cohort of Asians without prior cardiovascular disease.

Research design and methods This was a prospective population-based cohort study in Singapore comprising participants from the three major Asian ethnic groups: Chinese, Malays and Indians, with baseline examination in 2004-2011. Participants with type 1 diabetes and those with cardiovascular disease at baseline were excluded. Type 2 diabetes, Hemoglobin A1c (HbA1c) levels and presence of microvascular complications (diabetic retinopathy and nephropathy) were defined at baseline. The primary outcome was all-cause mortality and major adverse cardiovascular events (MACEs), defined as a composite of cardiovascular mortality, myocardial infarction, stroke and revascularization, collected using a national registry.

Results A total of 8541 subjects were included, of which 1890 had type 2 diabetes at baseline. Subjects were followed for a median of 6.4 (IQR 4.8-8.8) years. Diabetes was a significant predictor of mortality (adjusted HR $1.74,95 \% \mathrm{Cl}$ 1.45 to $2.08, \mathrm{p}<0.001$ ) and MACE (adjusted HR $1.64,95 \% \mathrm{Cl}$ 1.39 to $1.93, p<0.001)$. In those with diabetes, higher $\mathrm{HbA1c}$ levels were associated with increased MACE rates (adjusted HR (per $1 \%$ increase) $1.18,95 \% \mathrm{Cl} 1.11$ to $1.26, \mathrm{p}<0.001$ ) but not mortality $(\mathrm{p}=0.115)$. Subjects with two microvascular complications had significantly higher mortality and MACE compared with those with only either microvascular complication (adjusted $p<0.05$ ) and no microvascular complication (adjusted $\mathrm{p}<0.05$ ).

Conclusion Diabetes is a significant predictor of mortality and cardiovascular morbidity in Asian patients without prior cardiovascular disease. Among patients with type 2 diabetes, poorer glycemic control was associated with increased MACE but not mortality rates. Greater burden of microvascular complications identified a subset of patients with poorer outcomes.

\section{Significance of this study}

What is already known about this subject?

- Type 2 diabetes causes significant morbidity and mortality. The impact of glycemic control on mortality and macrovascular disease in patients with diabetes is controversial. Although intensive glycemic control is known to have potential beneficial effects in reducing the risk of microvascular complications, the benefits in terms of macrovascular disease is gray and there may even possibly be a signal for harm with regards to mortality.

What are the new findings?

- Type 2 diabetes predicts mortality and cardiovascular morbidity in Asian patients without prior cardiovascular disease.

- Poorer glycemic control is associated with increased major adverse cardiovascular events.

- Greater burden of microvascular complications results in poorer outcomes in patients with diabetes.

How might these results change the focus of research or clinical practice?

- Prevention and active management of type 2 diabetes and its microvascular complications may potentially aid in reducing cardiovascular morbidity.

\section{INTRODUCTION}

Diabetes mellitus (DM) is a global public health epidemic, affecting close to half a billion people in 2019. ${ }^{1}$ There is a huge burden of disease in Asia, with an estimated $60 \%$ of those with diabetes coming from Asia. ${ }^{2-5} \mathrm{DM}$ is associated with significant morbidity and mortality, with known deleterious effects on vascular beds causing microvascular complications such as retinopathy, nephropathy and neuropathy, and macrovascular complications such as myocardial infarction, stroke and peripheral vascular disease. ${ }^{6}$ 
There is increasing evidence that microvascular complications generally predate the onset of macrovascular disease, and in persons with diabetes, the presence of microvascular complications is associated with higher risk of macrovascular disease. ${ }^{7-14}$ While the majority of the data available showing the link between microvascular and macrovascular disease are based on Western populations, distinct ethnic differences in the development of microvascular and macrovascular diseases have been observed. ${ }^{8-101516}$ There are few Asian specific data. We recently demonstrated that microvascular disease resulted in increased mortality among Asian persons with diabetes. ${ }^{17}$

The impact of glycemic control on mortality and macrovascular disease in patients with diabetes is controversial. ${ }^{18-20}$ Although intensive glycemic control is known to have potential beneficial effect in reducing the risk of microvascular complications, there may be no benefit for macrovascular disease and even possibly a signal for harm with regards to mortality. ${ }^{18-20}$ Again, these studies were conducted in primarily Western populations, and their relevance to Asian persons is less clear. One study reported distinct differences between Asian and Western cohorts with glucose lowering, potentially causing increased mortality and coronary events in Western cohorts and increased microvascular events in Asians. ${ }^{16}$

To address these important gaps of the impact of diabetes and glycemic control on mortality and macrovascular disease, and whether the presence of microvascular complications affect these risks in Asians, we examined the association of type 2 diabetes, glycemic control and microvascular complications (primarily diabetic retinopathy and nephropathy) on mortality and cardiovascular outcomes in a multiethnic Asian cohort without known cardiovascular disease at baseline.

\section{METHODS}

\section{Study population}

The study population was derived from the Singapore Epidemiology of Eye Disease study, which comprised three inter-related cohort studies: the Singapore Malay Eyes Study (SiMES), the Singapore Indian Eye Study and the Singapore Chinese Eye Study (SCES), covering the three major Asian ethnics groups (Chinese, Malays and Indians) in Singapore. For the purposes of this study, the data included participants from 2004 to 2011 and participants with known prior cardiovascular disease (including stroke and coronary artery disease) and those with type 1 diabetes were excluded. The study design and methodology of the cohorts have been previously published. ${ }^{21}{ }^{22}$ In summary, a computer-generated simple random sample of Chinese, Malay and Indian names from the southwestern part of Singapore was provided to study team by The Ministry of Home Affairs. According to the 2000 Singapore Census, these residents were a fair representation of Singapore population in terms of age distribution, housing type and socioeconomic status. ${ }^{2324}$
The cohorts were then derived from a final sample using age-stratified random sampling strategy to generate equal representation of subjects from each decade from age 40 to 80 years old. All participants provided written consent. Subjects who agreed to participate underwent standardized interviews with detailed questionnaires, assessment of blood pressure, anthropometry, visual assessment and retinal photography. Blood and urine samples were collected and stored for biochemical analyses.

\section{Diabetes and microvascular disease}

Diagnosis of type 2 diabetes was confirmed if patient reported a physician's diagnosis of type 2 diabetes, use of diabetic medications, random plasma glucose $\geq 11.1 \mathrm{mmol} / \mathrm{L}$ and $/$ or Hbalc $\geq 6.5 .{ }^{25}$ Microvascular complications studied include the presence of diabetic retinopathy or nephropathy at baseline, and data on peripheral neuropathy were not collected. Diabetic retinopathy signs (microaneurysms, hemorrhages, or exudates) from the digital retinal photographs were analyzed by trained graders based on a standardized protocol. Retinopathy was defined as present if the retinopathy score (modified from the Airlie House classification system) was at level $\geq 15 .^{62627}$ The estimated glomerular filtration rate (eGFR) was derived using the Chronic Kidney Disease Epidemiology Collaboration equation. ${ }^{28}{ }^{29}$ Nephropathy was defined as the presence of chronic kidney disease (CKD) using an eGFR rate of $<60 \mathrm{~mL} / \mathrm{min} / 1.73 \mathrm{~m}^{2}$.

Urine data were available in a subset of the overall cohort of patients and albuminuria was calculated from the urine albumin:creatinine ratio (ACR). The Kidney Disease Improving Global Outcomes (KDIGO) staging nomenclature was used to define the risk of nephropathy (low, medium, high and very high) taking into account both ACR $(<30 \mathrm{mg} / \mathrm{g}, \geq 30-300 \mathrm{mg} / \mathrm{g}$ and $>300 \mathrm{mg} / \mathrm{g})$ and eGFR values in this subset of patients (online supplemental table 1). ${ }^{30}$

\section{Outcomes}

The primary outcome was all-cause mortality. The secondary outcome was major adverse cardiovascular event (MACE) defined as a composite of cardiovascular mortality, non-fatal myocardial infarction, non-fatal stroke and coronary revascularization (coronary artery bypass grafting and/or percutaneous coronary intervention). Outcome data were obtained by linkage to national registries, and all subjects were followed up to December 2014. All Singaporean residents are given a unique identification number that is linked with national death and disease registries. Death and cause of death was obtained from the Registry of Births and Deaths. ${ }^{31}$ Myocardial infarction data were obtained from the Singapore Myocardial Infarction Registry, and stroke data were obtained from the Singapore Stroke Registry, both under the purview of the National Registry of Diseases Office. ${ }^{31}$ Revascularization data were obtained from the Singapore Cardiac DataBank (SCDB), which serves as 
the national databank of cardiovascular procedures in the public sector where the vast majority of tertiary care is provided. ${ }^{32}$

\section{Statistical analysis}

Baseline descriptive statistics are stratified by presence of diabetes in the overall cohort and presence of diabetic complications in the subjects with diabetes. We presented data as means and plus SD or numbers and percentages, and tested differences between groups with analysis of variance (ANOVA) or the $\chi^{2}$ test correspondingly. For multivariable survival analysis for the primary and secondary outcomes, Cox regression analysis was used, and for the overall and diabetic cohort, models were adjusted for age, sex, ethnicity, body mass index (BMI), current smoking, systolic blood pressure and cholesterol. As eGFR and diabetes were important predictors of outcomes, we additionally adjusted for it in the overall cohort. In the diabetes cohort, however, eGFR was used to define CKD as a microvascular complication, hence not adjusted to avoid collinearity. Additionally, duration of diabetes was adjusted for in the diabetic cohort. Similar models were used in the subset of subjects with urine data $(n=1256)$. We also tested for any interaction between glycemic control (Hbalc $<8 \%$ vs Hbalc $\geq 8 \%$ ) and diabetic microvascular disease (none, one or both microvascular complications) on the outcomes of mortality and MACE. If significant interaction was present, the results were further stratified to determine if glycemic control affected the outcomes in the absence or presence of diabetic complications. Differences in survival were depicted with Kaplan-Meier graphs and tested with the log-rank test. All tests performed were two sided, and $\mathrm{p}$ values $<0.05$ were considered statistically significant. All analyses were performed with STATA V.14.0 (Stata Corp).

\section{RESULTS}

\section{Study population}

A total of 8541 subjects were included. The prevalence of type 2 diabetes was $22.1 \%(n=1890)$. The mean duration of diabetes was $8.3 \pm 8.7$ years. Subjects with diabetes were significantly older and had greater proportion of Indian ethnicity, higher BMI, greater proportion of hypertension and hyperlipidemia, lower proportion of current alcohol and smoking status, lower eGFR and higher urine ACR compared with subjects without diabetes (all $\mathrm{p}<0.001$ except $\mathrm{p}=0.027$ for alcohol status; table 1 ).

\section{Microvascular disease}

Of the subjects with diabetes, 987 had no microvascular complications, 677 had one microvascular complication (diabetic retinopathy or nephropathy) and 146 had both microvascular complications. Subjects with both microvascular complications had longer duration of diabetes compared with those with one microvascular complication or none (13.5 vs 10.3 vs 6.1 years, respectively, $\mathrm{p}<0.001)$. Subjects with both microvascular complications were also older, had greater proportion of hypertension, and had lower eGFR and higher urine ACR compared with those with one microvascular complication or none (all $\mathrm{p}<0.001$; table 2). Among the three races, a higher proportion of Malays had diabetic microvascular complications such as retinopathy or nephropathy compared with Chinese or Indians $(\mathrm{p}<0.001$; online supplemental table 2.

\section{Outcomes}

The median duration of follow-up was 6.4 (IQR 4.8-8.8) years.

\section{Mortality}

For the overall cohort, diabetes was a significant predictor of all-cause mortality (13.2\% vs $5.5 \%$, adjusted HR 1.74 , $\mathrm{p}<0.001)$. Subjects with diabetes with no microvascular complications had no significant difference in all-cause mortality compared non-diabetic subjects regardless of HbA1c levels ( $5.6 \%$ vs $5.5 \%, p=0.612$ for $\mathrm{HbA} 1 \mathrm{c}<8 \%$ and 7.4 vs $5.5 \%, p=0.354$ for $\mathrm{HbA} 1 \mathrm{c} \geq 8 \%$ ) (see online supplemental table 3 and figure 1A). In the overall cohort, higher systolic blood pressure (adjusted HR 1.009, $\mathrm{p}<0.001)$ but not higher total cholesterol $(\mathrm{p}=0.778)$ predicted for increased mortality.

Among those with diabetes, higher HbA1c levels, both as continuous variable $(\mathrm{p}=0.115)$ and as a categorical variable $(<6.5 / 7 \%$ vs $6.5 / 7-8 \%$ vs $\geq 8 \%) \quad(p>0.05$ for all) did not predict for mortality.

The presence of retinopathy $(17.3 \%$ vs $10.4 \%, \mathrm{p}<0.001)$ was a significant predictor of mortality on univariable analysis but its effect was attenuated on adjustment for confounders $(\mathrm{p}=0.074)$. Nephropathy $(32.8 \%$ vs $8.1 \%$, adjusted HR 2.34, $\mathrm{p}<0.001$ ) was a significant predictor of mortality. Subjects with both retinopathy and nephropathy had higher rates of all-cause mortality compared with those with no microvascular disease $(32.2 \%$ vs $6.3 \%$, adjusted HR 3.20, $\mathrm{p}<0.001$ ) and compared with those with either microvascular disease $(32.2 \%$ vs $18.9 \%$, adjusted HR 1.51, $\mathrm{p}=0.025)$. Subjects with either microvascular disease had higher rates of all-cause mortality compared with those with none (adjusted HR 2.13, $\mathrm{p}<0.001)$. There were no significant interactions between HbA1c and microvascular complications for all-cause mortality $(p=0.725)$. Ethnicity did not modify the association of the microvascular complications with mortality $\left(\mathrm{P}_{\text {interaction }}=0.101\right) \quad($ see table 3 and figure 2A). In the diabetic cohort, higher systolic blood pressure (adjusted HR 1.012, $\mathrm{p}<0.001)$ but not higher total cholesterol $(p=0.294)$ predicted for increased mortality.

In the subset of patients with albuminuria data $(\mathrm{n}=1256)$, those with ACR $>300 \mathrm{mg} / \mathrm{g}$ had significantly higher rate of mortality compared with those with ACR $<30 \mathrm{mg} / \mathrm{g}(36.8 \%$ vs $4.8 \%$, adjusted HR $6.63, \mathrm{p}<0.001)$. Defining nephropathy using both ACR and eGFR data based on the standardized risk matrix from the maO guidelines also showed subjects classified as moderate and above risk of nephropathy had higher mortality 
Table 1 Baseline characteristics of overall cohort

\begin{tabular}{|c|c|c|c|c|c|}
\hline & No diabetes & & Diabetes & & \\
\hline Characteristics & $(\mathrm{N}=6651)$ & & $(\mathrm{N}=1890)$ & & $P$ value \\
\hline Age (years) & 57.2 & 10.1 & 61.5 & 9.8 & $<0.001$ \\
\hline Ethnicity & & & & & $<0.001$ \\
\hline Malay & 2165 & $32.6 \%$ & 623 & $32.9 \%$ & \\
\hline Indian & 1916 & $28.8 \%$ & 863 & $45.7 \%$ & \\
\hline Chinese & 2570 & $38.6 \%$ & 404 & $21.4 \%$ & \\
\hline Men & 3175 & $47.7 \%$ & 887 & $46.9 \%$ & 0.536 \\
\hline BMI $\left(\mathrm{kg} / \mathrm{m}^{2}\right)$ & 25.0 & 4.6 & 26.7 & 4.6 & $<0.001$ \\
\hline Systolic BP (mm Hg) & 137.8 & 21.6 & 146 & 22.2 & $<0.001$ \\
\hline Diastolic BP $(\mathrm{mm} \mathrm{Hg})$ & 78.7 & 10.6 & 78.1 & 10.2 & 0.029 \\
\hline $\mathrm{HbA} 1 \mathrm{c}(\%)$ & 5.8 & 0.5 & 8.0 & 1.8 & $<0.001$ \\
\hline Total cholesterol (mmol/L) & 5.6 & 1.0 & 5.1 & 1.2 & $<0.001$ \\
\hline $\mathrm{HDL}(\mathrm{mmol} / \mathrm{L})$ & 1.3 & 3.4 & 1.2 & 0.3 & $<0.001$ \\
\hline LDL (mmol/L) & 3.5 & 0.9 & 3.1 & 1.0 & $<0.001$ \\
\hline Blood glucose (mmol/L) & 5.6 & 1.2 & 10.7 & 5.1 & $<0.001$ \\
\hline Duration of diabetes (years) & & & 8.3 & 8.7 & - \\
\hline Therapy for diabetes & & & & & - \\
\hline Diet only & & & 105 & $6.4 \%$ & \\
\hline Insulin only & & & 8 & $0.5 \%$ & \\
\hline Oral medication only & & & 766 & $46.8 \%$ & \\
\hline Oral medication and insulin & & & 91 & $5.6 \%$ & \\
\hline Hypertension & 3598 & $54.2 \%$ & 1451 & $76.9 \%$ & $<0.001$ \\
\hline Hyperlipidaemia & 2499 & $37.6 \%$ & 1088 & $59.4 \%$ & $<0.001$ \\
\hline Retinopathy/chronic kidney disease & 843 & $12.9 \%$ & 823 & $43.5 \%$ & $<0.001$ \\
\hline Current smoking & 1111 & $16.7 \%$ & 234 & $12.4 \%$ & $<0.001$ \\
\hline Current alcohol & 582 & $8.8 \%$ & 135 & $7.2 \%$ & 0.027 \\
\hline Estimated GFR, $\mathrm{mL} / \mathrm{min} / 1.73 \mathrm{~m}^{2}$ & 86 & 18.1 & 80.2 & 22.9 & $<0.001$ \\
\hline Albumin:creatinine ratio* & 33 & 186 & 156 & 1031 & $<0.001$ \\
\hline
\end{tabular}

Data presented are mean and SD, or count and proportion for continuous and categorical variables respectively.

*Albumin creatinine ratio available in 4841 and 1256 participants without and with diabetes, respectively.

BMI, body mass index; BP, blood Pressure; GFR, glomerular filtration rate; HbA1c, hemoglobin A1c; HDL, High-density lipoprotein; LDL, lowdensity lipoprotein.

( $12.8 \%$ vs $3.8 \%$, adjusted HR $2.11, \mathrm{p}=0.002)$ than those classified as low risk of nephropathy (see online supplemental table 4).

\section{Major adverse cardiovascular events}

For the overall cohort, diabetes was a significant predictor of MACE $(14.6 \%$ vs $6.8 \%$, adjusted HR 1.64, p<0.001). Patients with diabetes with $\mathrm{HbAlc}<8 \%$ and either no microvascular disease or retinopathy alone had no significant difference in MACE compared with non-diabetic subjects $(6.5 \%$ vs $6.8 \%, \mathrm{p}=0.981$ for no microvascular disease and $7.9 \%$ vs $6.8 \%, \mathrm{p}=0.486$ for retinopathy alone). Patients with diabetes with $\mathrm{HbA} 1 \geq 8 \%$ had significantly higher MACE rates compared with non-diabetics regardless of the presence of microvascular disease $(p<0.05$ for all) (see online supplemental online supplemental table
3 and figure 1B). In the overall cohort, higher systolic blood pressure (adjusted HR 1.008, $\mathrm{p}<0.001$ ) and higher total cholesterol (adjusted HR 1.079, $\mathrm{p}=0.019$ ) predicted for increased MACE.

Among those with diabetes, higher HbA1c levels as continuous variable was a significant predictor of mortality. Using a cut-off of $6.5 \%$ and $8 \%$, HbA1c $\geq 8 \%$ was a significant predictor of MACE $(19.3 \%$ vs $10.8 \%$, adjusted HR 1.87, p=0.002) compared with HbAlc $<6.5 \%$. There were no significant differences in MACE rates between HbA1c $6.5 \%-8 \%$ and $<6.5 \%$. Comparing $\mathrm{HbA1c}<7 \%$ versus $7 \%-8 \%$ versus $\geq 8 \%$ yielded similar results as previously stated. Presence of retinopathy was a significant predictor of MACE on univariable analysis $(p=0.003)$, but its effect was attenuated on adjustment 


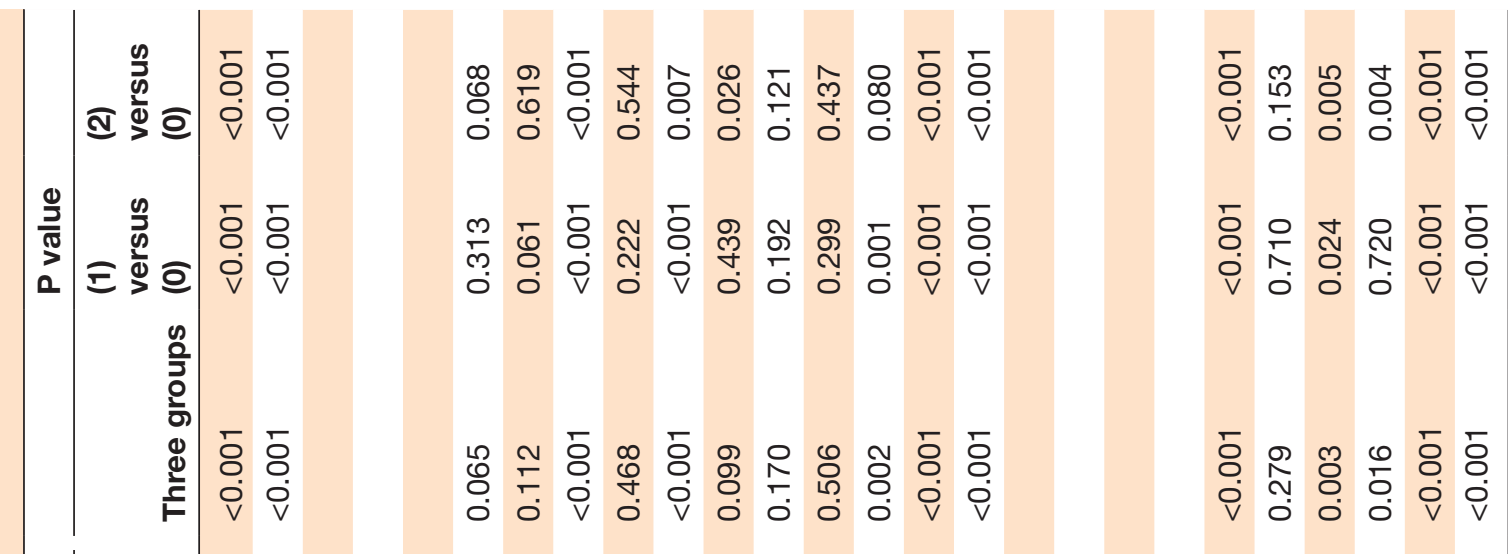

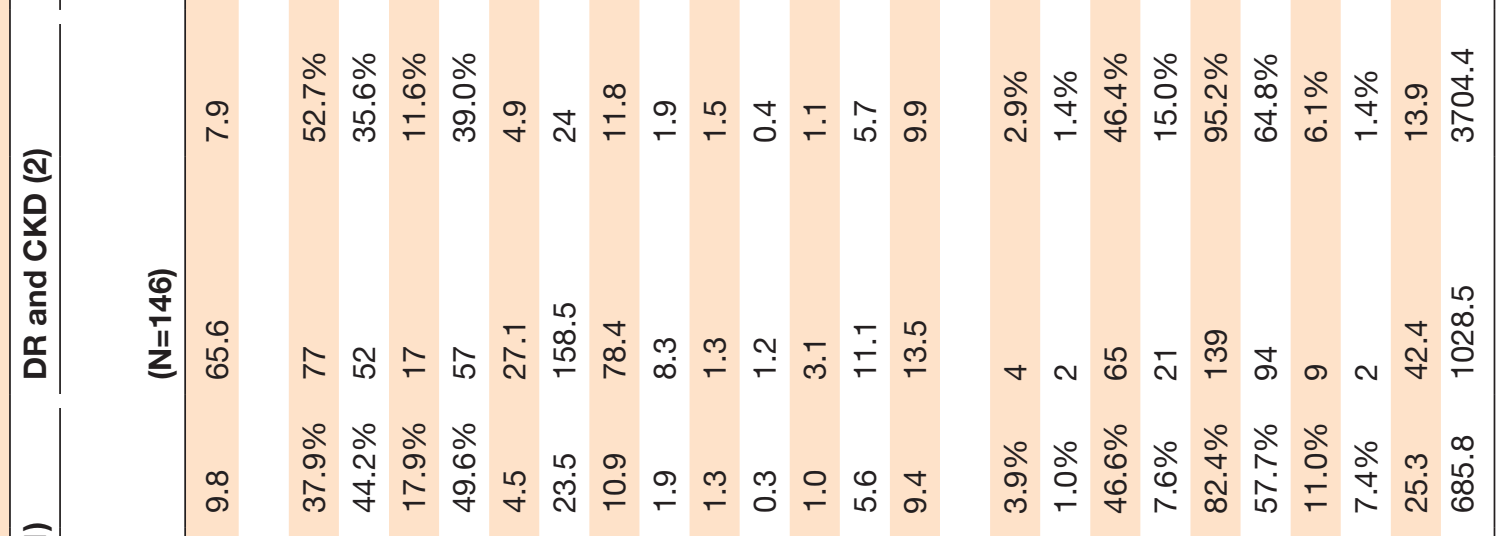

苞

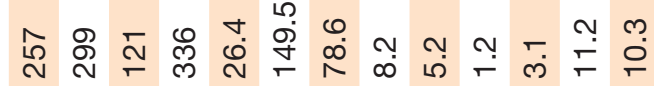

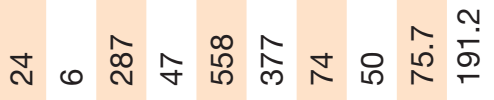

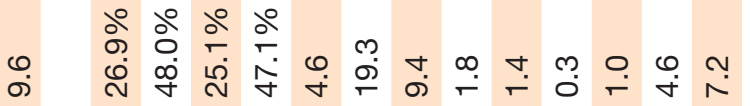

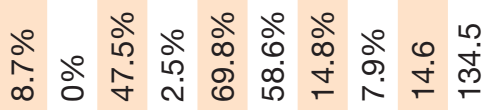

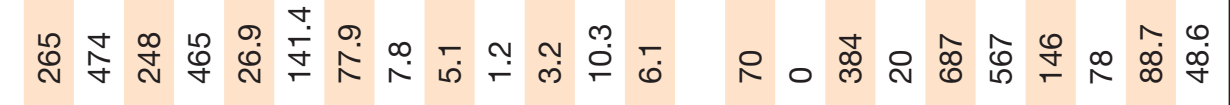

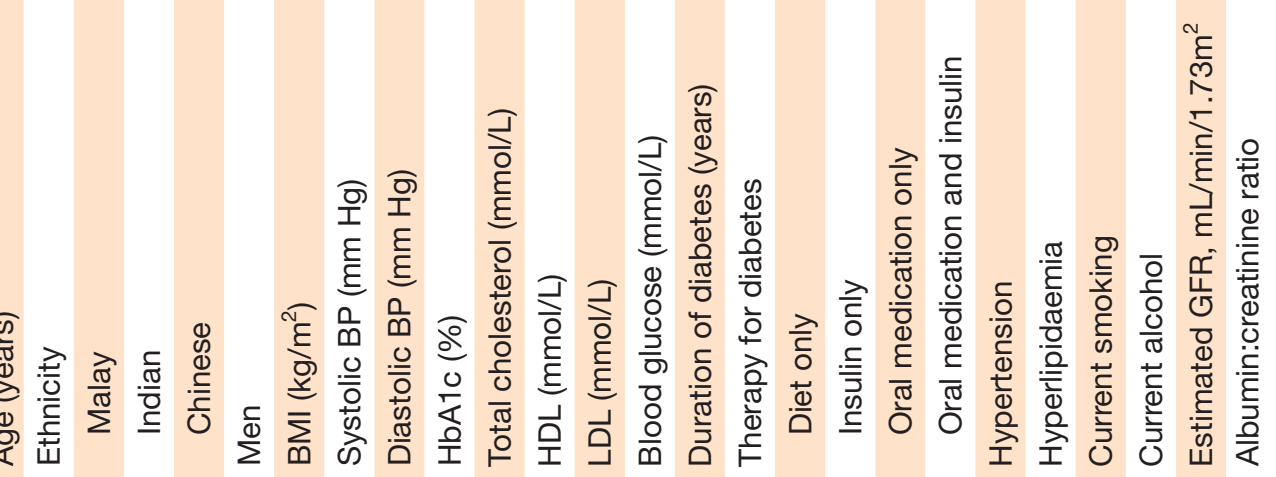


Fig 1a.

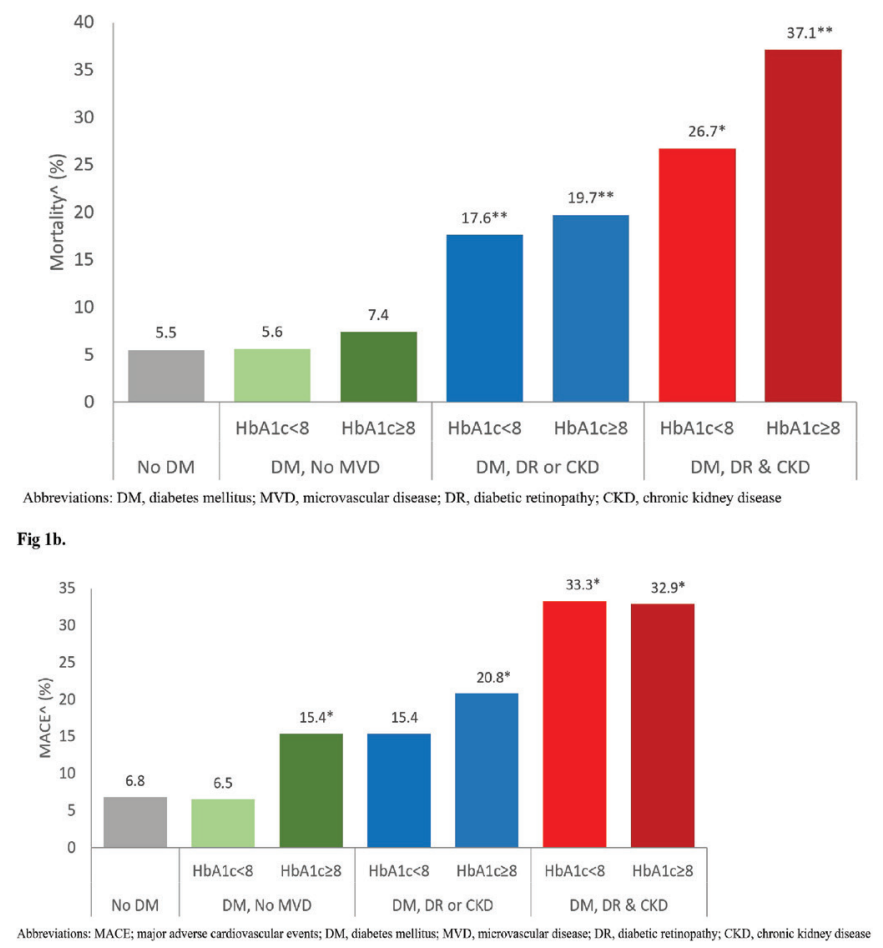

Figure 1 (A). Impact of diabetes, glycemic control, and microvascular disease on crude rates of all-cause mortality. $\wedge$ Median follow-up of 6.4 years. ${ }^{*}$ Adjusted $p<0.05$, ${ }^{* *}$ adjusted $\mathrm{p}<0.01$ compared with non-diabetes. (B). Impact of diabetes, glycemic control, and microvascular disease on crude rates of MACE. $\wedge$ Median follow-up of 6.4 years. *Adjusted $p<0.05$, ${ }^{\star *}$ adjusted $\mathrm{p}<0.01$ compared with non-diabetes. CKD, chronic kidney disease; DM, diabetes mellitus; DR, diabetic retinopathy; MACE, major adverse cardiovascular event; MVD, microvascular disease.

for confounders $(\mathrm{p}=0.278)$. Nephropathy was a significant predictor of MACE $(31.0 \%$ vs $10.5 \%$, HR 1.88 , $\mathrm{p}<0.001)$. Subjects with both retinopathy and nephropathy had higher rates of MACE compared with those with no complications $(32.9 \%$ vs $9.5 \%$, adjusted HR 2.23, $\mathrm{p}<0.001)$ and compared with those with either microvascular disease $(32 \%$ vs $18.9 \%$, adjusted HR 1.59 , $\mathrm{p}=0.010)$. Subjects with either microvascular disease had higher rates of MACE compared with those with none (adjusted HR 1.40, $\mathrm{p}=0.021$ ). There were significant interactions between HbA1c and microvascular complications for MACE $(p=0.031)$. In the absence of microvascular disease, subjects with $\mathrm{HbA1c} \geq 8 \%$ had significantly higher MACE compared with those with HbAlc $<8 \%$ (adjusted HR 2.63, $\mathrm{p}<0.001$ ). In the presence of microvascular disease, higher $\mathrm{HbA1c}$ levels did not have a significant impact on MACE ( $>>0.05)$. Ethnicity did not modify the association of the microvascular complications with MACE $\left(\mathrm{P}_{\text {interaction }}=0.203\right)$ (see table 3 and figure $\left.2 \mathrm{~B}\right)$. In the diabetic cohort, higher systolic blood pressure (adjusted HR 1.011, $\mathrm{p}=0.001$ ) but not higher total cholesterol $(\mathrm{p}=0.152)$ predicted for increased MACE.
In the subset of patients with albuminuria data, those with ACR $>300 \mathrm{mg} / \mathrm{g}$ had significantly higher rate of MACE compared with those with ACR $<30 \mathrm{mg} / \mathrm{g}$ (33.3\% vs $6.5 \%$, adjusted HR 5.46, $\mathrm{p}<0.001)$. Defining nephropathy using both ACR and eGFR data based on the standardized risk matrix from the KDIGO guidelines also showed subjects classified as moderate and above risk of nephropathy had higher MACE ( $18.2 \%$ vs $4.9 \%$, adjusted HR 3.12, $\mathrm{p}<0.001)$ than those classified as low risk of nephropathy (see online supplemental table 4 ).

\section{DISCUSSION}

We provide comprehensive long-term prospective data from Asia describing the impact of type two diabetes, glycemic control and burden of microvascular complications on mortality and cardiovascular outcomes. Our primary findings were first, in Asian persons, type 2 diabetes is associated with significant mortality and morbidity; second, among subjects with type 2 diabetes, poor glycemic control impacted on higher MACE but not mortality; third, while the impact of diabetic retinopathy on mortality and MACE was attenuated after adjustment for confounders, nephropathy, both in terms of low eGFR and degree of albuminuria, was independently associated with higher mortality and risk of MACE; and finally, increasing burden of microvascular complications portended increasingly poorer mortality and morbidity outcomes. Interestingly, persons with diabetes without microvascular disease had similar mortality as persons without diabetes regardless of $\mathrm{HbA1c}$ levels.

Diabetes is a well-established cardiovascular risk factor. Our results are consistent with a major observation in Western subjects suggested by Haffner $e t a l^{33}$, which show persons with diabetes without a history of myocardial infarction have a similar risk of future cardiac events as non-diabetes with prior myocardial infarction. Numerous studies have shown unequivocally the negative impact of diabetes on survival. ${ }^{61734}$ Our study findings lend further support to this in an Asian cohort.

Of greater interest is the impact of diabetic control and microvascular disease in those with diabetes.

Early epidemiologic studies have a possible correlation between poorer glycemic control and adverse outcomes. ${ }^{35}$ However, contrary to the expected benefits of intensive glycemic control, more contemporary large randomised controlled trials have not shown such results. The Action to Control Cardiovascular Risk in Diabetes trial was ceased earlier after a median follow-up of 3.7 years due to increased all-cause mortality in the intensive glycemic control (Hbalc $<6 \%)$ compared with the standard glycemic control (Hbalc 7\%-7.9\%). ${ }^{17}$ The Action in Diabetes and Vascular Disease: Preterax and Diamicron Modified Release Controlled Evaluation trial showed that intensive blood glucose control (target HbAlc $\leq 6.5 \%$ ) using gliclazide or a strategy of standard glucose control (median HbAlc 7.5\%) reduced nephropathy but not retinopathy, major macrovascular events or mortality. ${ }^{18}$ 


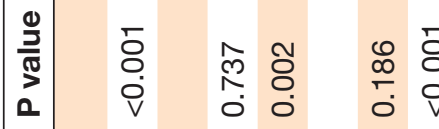

ஸे $\bar{~} \stackrel{\infty}{\infty} \infty$

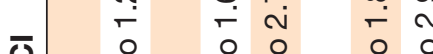

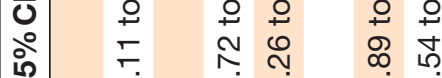

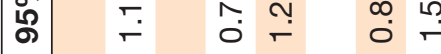

雚

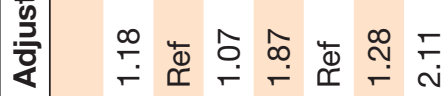

을

$\Phi$

岂

旁

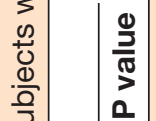

$\left|\begin{array}{c}\frac{0}{\frac{1}{T}} \\ \frac{1}{2}\end{array}\right|$

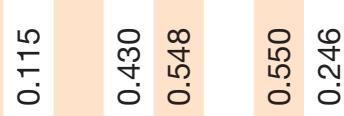

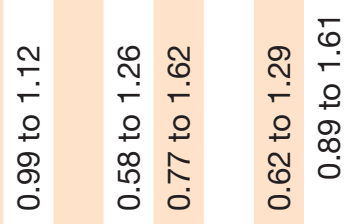

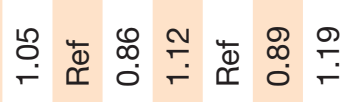

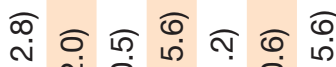
$=\stackrel{2}{=} \stackrel{5}{=}$

న্

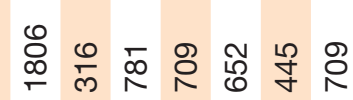

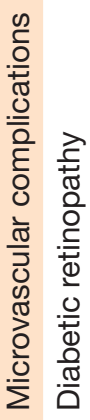

ซ ल ब

号 $\stackrel{0}{\text { N }}$

$\widetilde{\infty} \stackrel{0}{\sim 0}$

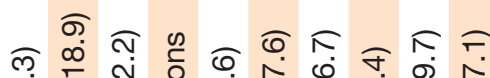

के

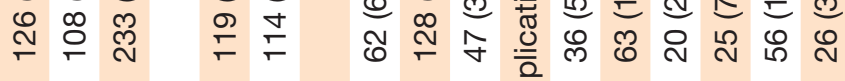

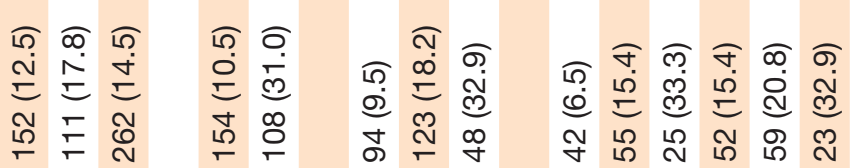

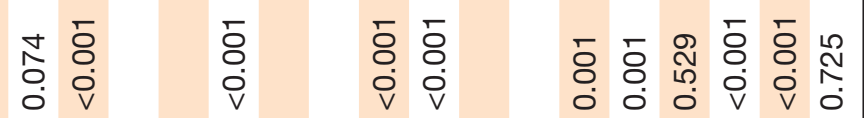

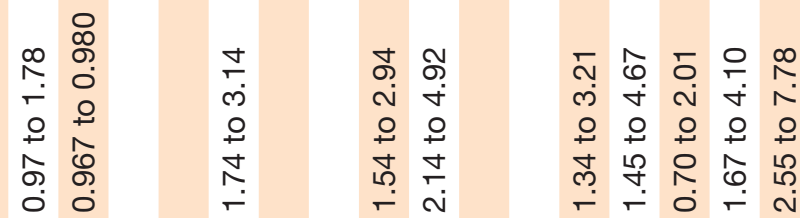

শ্ৰ

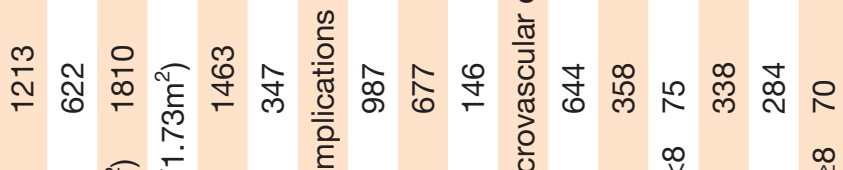

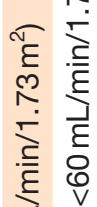

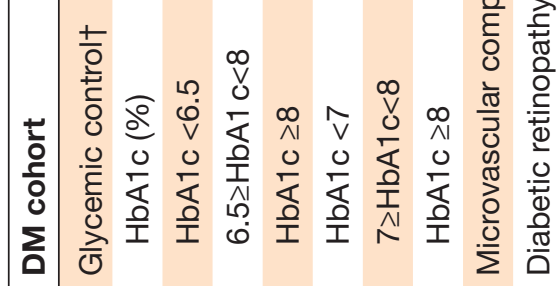

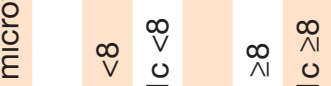

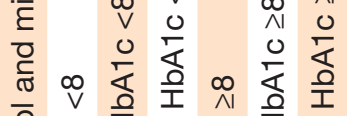

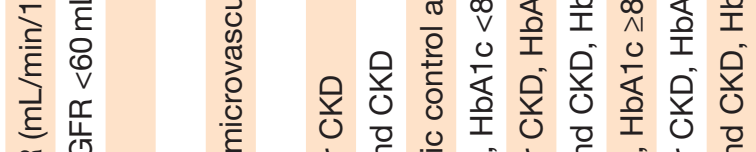

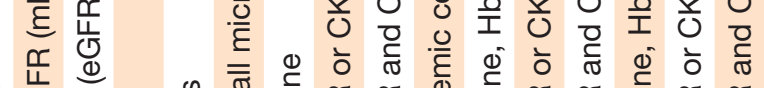

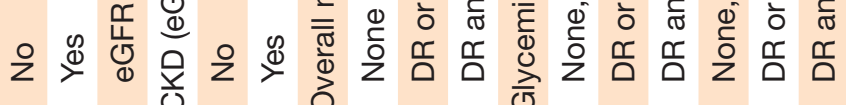


Fig 2a.

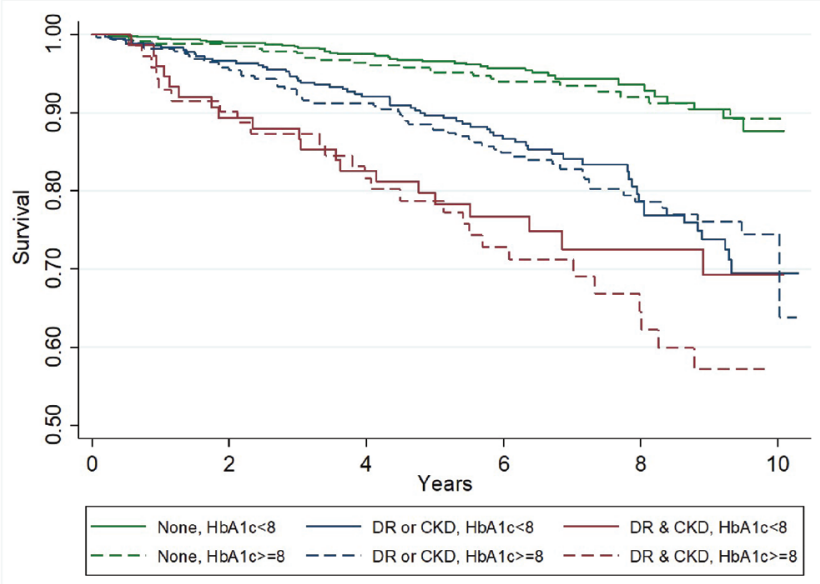

Fig 2b.

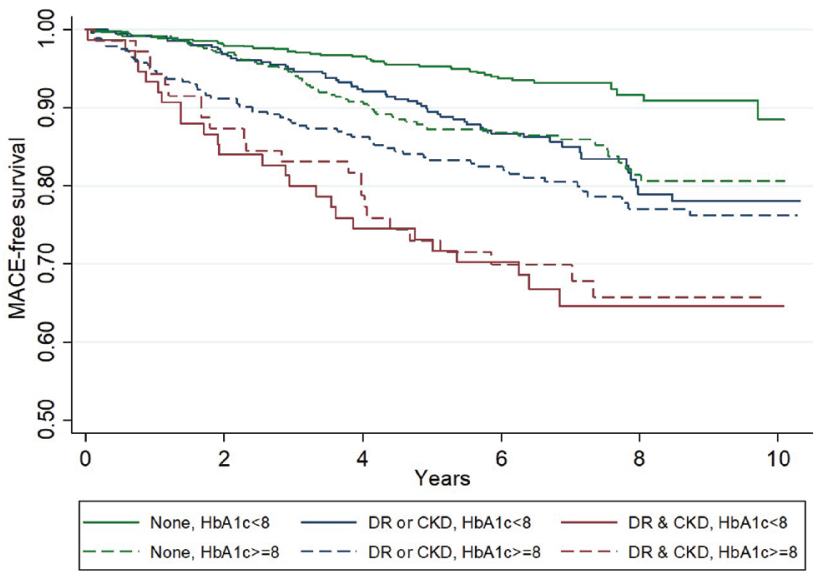

Figure 2 (A) Survival curves by glycemic control and burden of microvascular disease. (B) Major adverse cardiovascular events (MACE) curves by glycemic control and burden of microvascular disease. CKD, chronic kidney disease.

The Veterans Affairs Diabetes Trial showed that intensive glucose control (median HbAlc 6.9\%) compared with standard-therapy (median HbA1c 8.4\%) in patients with poorly controlled type 2 diabetes had no significant effect on microvascular complications, major cardiovascular events or death, with the exception of progression of albuminuria. ${ }^{20}$ In all three trials, there was a higher level of hypoglycemia in the intensive therapy arm, and this has been put forth to partially explain the lack of benefit of intensive control. ${ }^{18-20}$

Our study did not show any impact of HbA1c levels on mortality, although higher HbAlc levels were associated with increased MACE rates. The impact of HbA1c levels on MACE rates was seen mainly above a cut-off of $8 \%$. The differences in cut-offs and the non-randomized observational nature of our study should be taken into context when interpreting the later finding when compared with the equivocal findings of HbAlc on mortality/MACE rates from the above three randomized controlled trials. Of note, a meta-analysis including the above trials among others showed a similar neutral mortality signal with intensive glucose control but a significant reduction in MACE by $9 \% .^{37}$ The relationship between HbAlc and mortality is complex. Beyond RCTs, population-based observational studies have noted a possible J-shaped relationship between $\mathrm{HbAlc}$ and mortality with higher mortality at both ends of the spectrum of HbA1c levels. ${ }^{38}{ }^{39}$ In a case-control study of more than 30000 patients, HbAlc levels $<6.5 \%$ or $>9.0 \%$ were associated with increased mortality within 1 year. ${ }^{38} \mathrm{~A}$ meta-analysis of observational studies showed an increased risk of mortality at high and low $\mathrm{HbA1c}$ levels. ${ }^{39}$ In our study, there were numerically higher deaths at high and low HbAlc levels, although these did not reach statistical significance. Of note, the overall numbers in our study are significantly smaller and only included baseline HbAlc measurements. Studies looking at HbAlc trends have shown that both greater variability in $\mathrm{HbA1c} \mathrm{c}^{40}$ as well as worsening HbA1c patterns ${ }^{41}$ were associated with elevated risk of mortality.

We noted an interaction between HbAlc levels and microvascular disease for MACE. In the absence of microvascular disease, subjects with poor glycemic control had significantly higher MACE rates, while in the presence of microvascular disease, glycemic control did not have much impact on MACE. Microvascular disease appears to be a more predominant driver of adverse outcomes compared with level of glycemic control.

There is growing evidence of a relationship between diabetic retinopathy and cardiovascular disease. ${ }^{9}$ A large meta-analysis of 20 studies showed a significant relationship between diabetic retinopathy and an increased risk of all-cause mortality and cardiovascular events in both patients with type 2 and type 1 diabetes. ${ }^{42}$ We found independent associations with increased mortality and MACE on univariable analysis, but both effects were attenuated on multivariate analysis. In an earlier publication, we found that the DR was associated with higher risk of all-cause and cardiovascular mortality, but this association was weaker than that of CKD. ${ }^{17}$ This earlier study included subjects with both type 1 and 2 diabetes, and about 20\% had known cardiovascular disease.

Nephropathy is another well-investigated risk factor for cardiovascular disease. Nephropathy is classified by KDIGO guidelines based on both GFR category and albuminuria. ${ }^{20}$ Many studies evaluating the impact of CKD on CV outcomes do not look at both eGFR and albuminuria concurrently. In an earlier study, we found that CKD defined based on eGFR had significant impact on mortality, but albuminuria was not evaluated..$^{17}$ In those studies that include both eGFR and albuminuria data, there are some variations on the results. ${ }^{104344} \mathrm{~A}$ cohort study performed in Beijing of 1914 patients over a median follow-up period of 6.8 years showed that subjects who progressed to albuminuria of $\geq 30 \mathrm{mg} /$ day had a significant negative impact on cardiovascular outcomes but not those who progressed to eGFR $<60 \mathrm{~mL} / \mathrm{min} / 1.73$ $\mathrm{m}^{2}{ }^{23}$ In contrast, a Sri Lankan cohort of 2434 patients showed eGFR but not albuminuria predicted coronary heart disease. ${ }^{44}$ The Fenofibrate Intervention and Event Lowering in Diabetes study looked at 15773 in 19 
outpatient Italian diabetes clinics, CV risk was shown to increase with both declining eGFR and worsening albuminuria independently. ${ }^{10}$ Albuminuria of $\geq 30 \mathrm{mg} /$ day had an OR 1.26 (95\% CI 1.05 to 1.52 )) compared with reduced eGFR $<60 \mathrm{~mL} / \mathrm{min} / 1.73 \mathrm{~m}^{2}$, which had an OR of 1.52 (95\% CI 1.34 to 1.73)). When both combined the OR was 1.90 (95\% C I1.66 to 2.19)). The KDIGO consortium published a meta-analysis of pooled data from 14 studies to evaluate the effects of eGFR and albuminuria with mortality and renal outcomes. Among the 105872 patient cohort, both lower eGFR $\left(<60 \mathrm{~mL} / \mathrm{min} / 1.73 \mathrm{~m}^{2}\right)$ and degree of albuminuria were independent predictors of overall mortality. ${ }^{45}$ Importantly, it showed that worsening eGFR and albuminuria were exponentially related to mortality attributed to cardiovascular disease. In our study, when eGFR and albuminuria was independently analysed for MACE and mortality, both showed a strong correlation for increased events. When taken into combination based on the KDIGO matrix, those classified as moderate and above risk of nephropathy had higher rate of both mortality and MACE. Both eGFR and albuminuria are important parameters for the clinician to consider when assessing for renal microvascular disease and should not be taken in isolation.

Ethnic variation of both prevalence and complications of type 2 diabetes has been examined in many studies. ${ }^{1546}$ Despite the heterogeneity among Asians, they are often aggregated together as a comparator to other populations. In one large Chinese meta-analysis, the reported prevalence of diabetic retinopathy was reported $23 \%$, which is comparable with western cohorts and with our study of $24.6 \%$ among the Chinese ethnic subgroup. ${ }^{47}$ Studies from India reported a rate of diabetic retinopathy among the Indians ranging from $12 \%$ to $22.4 \%,{ }^{48-50}$ compared with $29.6 \%$ in our Indian ethnic subgroup. The microalbuminuria prevalence (MAP) study suggested Asian prevalence of microalbuminuria was $39.8 \%$, which is fairly similar to the $33.9 \%$ in our study. ${ }^{51}$ A study looking at ethnic variation in diabetes showed that Malay and Indian diabetic subjects had a higher risk of cardiovascular disease compared with Chinese, with no significant differences in all-cause mortality. In their study, the baseline cardiometabolic risk factor control was poorest in Malays followed by Indians. Malays also had higher severity of renal impairment and Indians the least. ${ }^{52}$ In our study, ethnicity did not modify the association of the microvascular complication with outcomes. A plethora of other factors like socioeconomic status, urban environment, visceral adiposity and insulin resistance among others may confound interethnic differences. The true weight of ethnicity's influence remains controversial and is work for further research.

While many studies have shown the negative impact of microvascular disease on outcomes, there are few data on the proportional burden on microvascular disease on outcomes. Our earlier study demonstrated excess all-cause and CV mortality with having increasing microvascular disease, but myocardial infarction and stroke events were not assessed. In a large UK population-based study of about 49000 patients, it was found that increasing burden of microvascular disease resulted in corresponding increase rates in MACE. ${ }^{8}$ Similarly, we found that those with two microvascular diseases fared worse than those with one, which in turn fared worse than those with none. The screening for retinopathy and nephropathy is simple and cost-effective involving regular retinal fundophotography and spot urine tests, respectively. Effective treatment exists for both complications such as laser and ACE inhibitor/ Angiotensin receptor blockers therapy, respectively. Our study highlights the detrimental nature of diabetes and concomitant microvascular disease. Significantly, those with diabetes but without microvascular disease had similar mortality rates compared with non-diabetics regardless of HbA1c levels. Public health policies and primary preventive measures should be considered to prevent the onset of diabetes and when diabetes is present to effectively prevent and deal with microvascular disease. The impact of glycemic control is more controversial and should be tailored to the individual patient taking into account the hypoglycemic risk. With the emergence of more contemporary diabetic agents, like sodium-glucose cotransporter-2 inhibitors, and its potential benefits on reducing progression of renal microvascular disease as well as cardiovascular outcomes, these provide further tools for the clinician to help the patient in fighting this disease. ${ }^{53}$

\section{Limitations}

The limitations of the study include the lack of data on the microvascular complication of neuropathy. These data were not routinely collected as part of the study and is unfortunately unavailable. Second, for this analysis, the level of glycemic control (HbAlc data) was only available at baseline and impact of changes in glycemic control over time would be the work of future studies. Longitudinal follow-up of glycemic control may demonstrate differing associations of HbAlc with outcomes as seen in prior studies. ${ }^{40} 41$ Third, cardiac revascularizations in the private sector may not be accounted for but the vast majority $(>80 \%)$ of tertiary care in Singapore is provided for in the public sector. Fourthly, the findings need to be validated with larger sample sizes and longer duration of follow-up. Lastly, the observational nature of this epidemiological study may have introduced biases that may not have been fully accounted for despite adjustment for confounders. In this observational study, causality between associations may be difficult to determine and the increased hazards of mortality and MACE may be due to shared pathways between microvascular and macrovascular complications. Nevertheless, this large prospective cohort provides real-world long-term epidemiological data on the disease.

\section{CONCLUSIONS}

Type 2 diabetes is a significant predictor of mortality and morbidity in Asian patients without prior cardiovascular disease. Among those with type 2 diabetes, poorer 
glycemic control was associated with increased MACE but not mortality rates. Greater burden of microvascular disease identified a subset of patients with significantly poorer outcomes. This highlights the importance of prevention and treatment strategies to mitigate the detrimental effects of this disease.

\section{Author affiliations}

${ }^{1}$ Department of Cardiology, National Heart Centre Singapore, Singapore

${ }^{2}$ Department of Ophthalmology, Singapore Eye Research Institute, Singapore

${ }^{3}$ Duke-NUS Medical School, Singapore

${ }^{4}$ Department of Ophthalmology and Visual Sciences, The Chinese University of Hong Kong, Hong Kong, Hong Kong

${ }^{5}$ Singapore Eye Research Institute, Singapore

Contributors JY, KA, WTT, T-YW and KKY conceived the study, performed the analysis, and wrote the manuscript together. DT, C-YC, CS and C-YC collected the data and participated in the manuscript writing. All authors have read and approved the final manuscript.

Funding This study was supported by the National Medical Research Council (grants OFLCG/001/2017, 0796/2003, 1149/2008, and STaR/003/2008) and the Biomedical Research Council (grant 08/1/35/19/550).

Disclaimer The funders had no role in the design and conduct of the study; collection, management, analysis, and interpretation of the data; preparation, review, or approval of the manuscript; and decision to submit the manuscript for publication

Competing interests This study was supported by the National Medical Research Council (grants OFLCG/001/2017, 0796/2003, 1149/2008, and STaR/003/2008) and the Biomedical Research Council (grant 08/1/35/19/550). T-YW reported personal fees from Allergan, Bayer, Boehringer Ingelheim, Genentech, Merck, Novartis, Oxurion (formerly ThromboGenics), and Roche outside the submitted work; and serving as cofounder of plano and EyRiS.

Patient consent for publication Not required.

Ethics approval This study was performed in accordance with the tenets of the Declaration of Helsinki and ethics approval was obtained from the Institutional Review Board at the Singapore Eye Research Institute, the National University of Singapore and Singapore General Hospital. Written informed consent was also provided by participants.

Provenance and peer review Not commissioned; externally peer reviewed.

Data availability statement Data are available on reasonable request. As the study involves human participants, the data cannot be made freely available in the article or a public repository owing to ethical restrictions. Nevertheless, the data are available from the Singapore Eye Research Institutional Ethics Committee for researchers who meet the criteria for access to confidential data. Interested researchers can send data access requests to the Singapore Eye Research Institute at seri@seri.com.sg.

Supplemental material This content has been supplied by the author(s). It has not been vetted by BMJ Publishing Group Limited (BMJ) and may not have been peer-reviewed. Any opinions or recommendations discussed are solely those of the author(s) and are not endorsed by BMJ. BMJ disclaims all liability and responsibility arising from any reliance placed on the content. Where the content includes any translated material, BMJ does not warrant the accuracy and reliability of the translations (including but not limited to local regulations, clinical guidelines, terminology, drug names and drug dosages), and is not responsible for any error and/or omissions arising from translation and adaptation or otherwise.

Open access This is an open access article distributed in accordance with the Creative Commons Attribution Non Commercial (CC BY-NC 4.0) license, which permits others to distribute, remix, adapt, build upon this work non-commercially, and license their derivative works on different terms, provided the original work is properly cited, appropriate credit is given, any changes made indicated, and the use is non-commercial. See: http://creativecommons.org/licenses/by-nc/4.0/.

\section{ORCID iDs}

Kamalesh Anbalakan http://orcid.org/0000-0001-8648-6774

Carol Yim Cheung http://orcid.org/0000-0002-9672-1819

Charumathi Sabanayagam http://orcid.org/0000-0002-4042-4719
Khung Keong Yeo http://orcid.org/0000-0002-5457-4881

\section{REFERENCES}

1 Saeedi P, Petersohn I, Salpea P, et al. Global and regional diabetes prevalence estimates for 2019 and projections for 2030 and 2045: Results from the International Diabetes Federation Diabetes Atlas, $9^{\text {th }}$ edition. Diabetes Res Clin Pract 2019;157:107843.

2 Yoon K-H, Lee J-H, Kim J-W, et al. Epidemic obesity and type 2 diabetes in Asia. Lancet 2006;368:1681-8.

3 Yang SH, Dou KF, Song WJ. Prevalence of diabetes among men and women in China. N Engl J Med 2010;362:1090-101.

4 Chan JCN, Malik V, Jia W, et al. Diabetes in Asia: epidemiology, risk factors, and pathophysiology. JAMA 2009;301:2129-40.

5 Nanditha A, Ma RCW, Ramachandran A, et al. Diabetes in Asia and the Pacific: implications for the global epidemic. Diabetes Care 2016;39:472-85.

6 Fowler MJ. Microvascular and macrovascular complications of diabetes. Clinical Diabetes 2008;26:77-82.

7 Pálsson R, Patel UD. Cardiovascular complications of diabetic kidney disease. Adv Chronic Kidney Dis 2014;21:273-80.

8 Brownrigg JRW, Hughes CO, Burleigh D, et al. Microvascular disease and risk of cardiovascular events among individuals with type 2 diabetes: a population-level cohort study. Lancet Diabetes Endocrinol 2016:4:588-97.

9 Miettinen H, Haffner SM, Lehto S, et al. Retinopathy predicts coronary heart disease events in NIDDM patients. Diabetes Care 1996;19:1445-8.

10 Solini A, Penno G, Bonora E, et al. Diverging association of reduced glomerular filtration rate and albuminuria with coronary and noncoronary events in patients with type 2 diabetes: the renal insufficiency and cardiovascular events (RIACE) Italian multicenter study. Diabetes Care 2012;35:143-9.

11 Xie J, Ikram MK, Cotch MF, et al. Association of diabetic macular edema and proliferative diabetic retinopathy with cardiovascular disease: a systematic review and meta-analysis. JAMA Ophthalmol 2017; 135:586-93.

12 Cheung N, Wang JJ, Rogers SL, et al. Aric (atherosclerosis risk in communities) study Investigators. diabetic retinopathy and risk of heart failure. J Am Coll Cardiol 2008;51:1573-8.

13 Cheung N, Wong TY. Diabetic retinopathy and systemic vascular complications. Prog Retin Eye Res 2008;27:161-76.

14 Cheung N, Wang JJ, Klein R, et al. Diabetic retinopathy and the risk of coronary heart disease: the Atherosclerosis risk in Communities study. Diabetes Care 2007;30:1742-6.

15 Spanakis EK, Golden SH. Race/ethnic difference in diabetes and diabetic complications. Curr Diab Rep 2013;13:814-23.

$16 \mathrm{Li} \mathrm{J}$, Dong Y, Wu T, et al. Differences between Western and Asian type 2 diabetes patients in the incidence of vascular complications and mortality: a systematic review of randomized controlled trials on lowering blood glucose. J Diabetes 2016;8:824-33.

17 Sabanayagam C, Chee ML, Banu R, et al. Association of diabetic retinopathy and diabetic kidney disease with all-cause and cardiovascular mortality in a multiethnic Asian population. JAMA Netw Open 2019;2:e191540.

18 ADVANCE Collaborative Group, Patel A, MacMahon S, et al. Intensive blood glucose control and vascular outcomes in patients with type 2 diabetes. N Engl J Med 2008;358:2560-72.

19 Action to Control Cardiovascular Risk in Diabetes Study Group, Gerstein HC, Miller ME, et al. Effects of intensive glucose lowering in type 2 diabetes. N Engl J Med 2008;358:2545-59.

20 Duckworth W, Abraira C, Moritz T, et al. Glucose control and vascular complications in veterans with type 2 diabetes. $N$ Engl $J$ Med 2009;360:129-39.

21 Foong AWP, Saw S-M, Loo J-L, et al. Rationale and methodology for a population-based study of eye diseases in Malay people: the Singapore Malay eye study (SiMES). Ophthalmic Epidemiol 2007; 14:25-35.

22 Lavanya R, Jeganathan VSE, Zheng Y, et al. Methodology of the Singapore Indian Chinese cohort (SICC) eye study: quantifying ethnic variations in the epidemiology of eye diseases in Asians. Ophthalmic Epidemiol 2009;16:325-36.

23 L B. Singapore census of population 2000: statistical release 1demographic characteristics. Singapore: Department of Statistics, 2001.

24 L B. Singapore census of population 2000: statistical release 5Households and housing. Singapore: Department of Statistics, 2001.

25 American Diabetes Association. Standards of medical care in diabetes--2010. Diabetes Care 2010;33 Suppl 1:S11-61.

$26 \mathrm{Ho} \mathrm{H}$, Cheung CY, Sabanayagam C, et al. Retinopathy signs improved prediction and reclassification of cardiovascular disease risk in diabetes: a prospective cohort study. Sci Rep 2017;7:41492. 
27 Tan GS, Gan A, Sabanayagam C, et al. Ethnic differences in the prevalence and risk factors of diabetic retinopathy: the Singapore epidemiology of eye diseases study. Ophthalmology 2018;125:529-36.

28 Levey AS, Stevens LA, Schmid CH, et al. A new equation to estimate glomerular filtration rate. Ann Intern Med 2009;150:604-12.

29 Sabanayagam C, Wong TY, Tai ES. The CKD-EPI equation and MDRD study equation find similar prevalence of chronic kidney disease in Asian populations. Ann Intern Med 2009;151:892-3.

30 Kidney Disease: Improving Global Outcomes (KDIGO) CKD Work Group. KDIGO 2012 clinical practice guideline for the evaluation and management of chronic kidney disease. Kidney inter 2013;3:1-150.

31 National Registry of Diseases Office. Available: https://www.nrdo. gov.sg/

32 Yeo KK, Ong H-Y, Chua T, et al. Building a Longitudinal National Integrated Cardiovascular Database - Lessons Learnt From SingCLOUD - . Circ Rep 2020;2:33-43.

33 Haffner SM, Lehto S, Rönnemaa T, et al. Mortality from coronary heart disease in subjects with type 2 diabetes and in nondiabetic subjects with and without prior myocardial infarction. New England Journal of Medicine 1998;339:229-34.

34 Rao Kondapally Seshasai S, Kaptoge S, Thompson A, et al. Diabetes mellitus, fasting glucose, and risk of cause-specific death. N Engl J Med 2011;364:829-41.

35 Selvin E, Marinopoulos S, Berkenblit G, et al. Meta-Analysis: glycosylated hemoglobin and cardiovascular disease in diabetes mellitus. Ann Intern Med 2004;141:421-31.

36 Gerstein HC, Pogue J, Mann JFE, et al. The relationship between dysglycaemia and cardiovascular and renal risk in diabetic and non-diabetic participants in the hope study: a prospective epidemiological analysis. Diabetologia 2005:48:1749-55.

37 Control Group, Turnbull FM, Abraira C, et al. Intensive glucose control and macrovascular outcomes in type 2 diabetes. Diabetologia 2009;52:2288-98

38 Nicholas J, Charlton J, Dregan A, et al. Recent $\mathrm{HbA} 1 \mathrm{c}$ values and mortality risk in type 2 diabetes. population-based case-control study. PLoS One 2013;8:e68008.

39 Arnold LW, Wang Z. The HbA1c and all-cause mortality relationship in patients with type 2 diabetes is $\mathrm{J}$-shaped: a meta-analysis of observational studies. Rev Diabet Stud 2014;11:138-52.

40 Kaze AD, Santhanam P, Erqou S, et al. Long-Term variability of glycemic markers and risk of all-cause mortality in type 2 diabetes: the look ahead study. BMJ Open Diabetes Res Care 2020;8:e001753.

41 Luo M, Lim WY, Tan CS, et al. Longitudinal trends in $\mathrm{HbA} 1 \mathrm{c}$ and associations with comorbidity and all-cause mortality in Asian patients with type 2 diabetes: a cohort study. Diabetes Res Clin Pract 2017:133:69-77.

42 Kramer CK, Rodrigues TC, Canani LH, et al. Diabetic retinopathy predicts all-cause mortality and cardiovascular events in both type 1 and 2 diabetes: meta-analysis of observational studies. Diabetes Care 2011;34:1238-44.

43 Zhang X-L, Yuan M-X, Wan G, et al. The effects of AER and eGFR on outcomes of CVD in patients with T2DM in an urban community over 8 years of multifactorial treatment: the Beijing communities diabetes study 18. Ther Clin Risk Manag 2018;14:1537-45.

44 Weerarathna $\mathrm{T}$, Liyanage $\mathrm{G}$, Herath $\mathrm{M}$, et al. Value of estimated glomerular filtration rate and albuminuria in predicting cardiovascular risk in patients with type 2 diabetes without cardiovascular disease. Biomed Res Int 2018;2018:1-5.

45 Chronic Kidney Disease Prognosis Consortium, Matsushita K, van der Velde $\mathrm{M}$, et al. Association of estimated glomerular filtration rate and albuminuria with all-cause and cardiovascular mortality in general population cohorts: a collaborative meta-analysis. Lancet 2010;375:2073-81

$46 \mathrm{Ma} \mathrm{RCW}$, Chan JCN. Type 2 diabetes in East Asians: similarities and differences with populations in Europe and the United States. Ann N Y Acad Sci 2013;1281:64-91.

47 Liu L, Wu X, Liu L, et al. Prevalence of diabetic retinopathy in mainland China: a meta-analysis. PLoS One 2012;7:e45264.

48 Rema M, Premkumar S, Anitha B, et al. Prevalence of diabetic retinopathy in urban India: the Chennai urban rural epidemiology study (cures) eye study, I. Invest Ophthalmol Vis Sci 2005;46:2328-33.

49 Dandona L, Dandona R, Naduvilath TJ, et al. Population based assessment of diabetic retinopathy in an urban population in southern India. Br J Ophthalmol 1999;83:937-40.

50 Ramachandran A, Snehalatha C, Vijay V, et al. Impact of poverty on the prevalence of diabetes and its complications in urban southern India. Diabet Med 2002:19:130-5.

51 Wu AYT, Kong NCT, de Leon FA, et al. An alarmingly high prevalence of diabetic nephropathy in Asian type 2 diabetic patients: the microalbuminuria prevalence (MAP) study. Diabetologia 2005;48:17-26

$52 \mathrm{Liu} \mathrm{JJ}$, Lim SC, Yeoh LY, et al. Ethnic disparities in risk of cardiovascular disease, end-stage renal disease and all-cause mortality: a prospective study among Asian people with type 2 diabetes. Diabet Med 2016;33:332-9.

53 Zelniker TA, Wiviott SD, Raz I, et al. SGLT2 inhibitors for primary and secondary prevention of cardiovascular and renal outcomes in type 2 diabetes: a systematic review and meta-analysis of cardiovascular outcome trials. Lancet 2019;393:31-9. 